\title{
The Frequency of Infectious Diseases in Manzhouli Port from 2012 to 2014
}

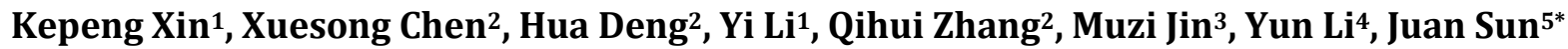 \\ ${ }^{1}$ Manzhouli Entry-Exit Inspection and Quarantine Bureau, Manzhouli, China \\ ${ }^{2}$ Manzhouli International Travel Healthcare Center, Manzhouli, China \\ ${ }^{3}$ Inner Mongolia International Travel Healthcare Center, Hohhot, China \\ ${ }^{4}$ Inner Mongolia Health Supervision, Hohhot, China \\ ${ }^{5}$ Inner Mongolia Medical University, Hohhot, China \\ Email: "sj6840@163.com
}

Received 30 November 2015; accepted 6 March 2016; published 9 March 2016

Copyright (C) 2016 by authors and Scientific Research Publishing Inc.

This work is licensed under the Creative Commons Attribution International License (CC BY). http://creativecommons.org/licenses/by/4.0/

c) (i) Open Access

\begin{abstract}
The aim of this study was to determine the frequency of infectious diseases among people entering/exiting via Manzhouli port. We analyzed infectious disease data from the Manzhouli International Travel Healthcare Center covering 2012 through 2014, as well as performed several laboratory tests to measure rates of infection. The frequencies of infectious diseases as well as their association with occupation and year of occurrence were calculated for people entering and exiting via the port. The total proportion of infectious diseases measured was $2.18 \%$. Hepatitis $B$ was the most commonly occurring at $1.68 \%$, followed by syphilis, hepatits $C$ and HIV, which were $0.23 \%$, $0.21 \%$ and $0.04 \%$, respectively. Contract workers, traffic staff, foreigners and those married abroad were more likely to be infected. Furthermore, there were significant differences among three years. Strategies should be developed and preventive policies should be implemented aimed at protecting the at risk populations at Manzhouli port, especially with regard to contract workers, traffic staff, foreigners and those married abroad.
\end{abstract}

\section{Keywords}

Infectious Disease, Detection Rate, Entry/Exit Screening, Occupation, Manzhouli Port

\section{Introduction}

Infectious diseases are a globally important issue. In developed countries, sexually transmitted diseases and viral

${ }^{*}$ Corresponding author.

How to cite this paper: Xin, K.P., Chen, X.S., Deng, H., Li, Y., Zhang, Q.H., Jin, M.Z., Li, Y. and Sun, J. (2016) The Frequency of Infectious Diseases in Manzhouli Port from 2012 to 2014. Advances in Infectious Diseases, 6, 1-6.

http://dx.doi.org/10.4236/aid.2016.61001 
hepatitis are the main ones under surveillance. However, for the populations in developing countries, infectious diseases are still the primary cause of death. For example, about 6.4 million people in China had infections in 2013 , leading to the death of 16,592 people [1]. While the mortality of infectious diseases was particularly high in 2013, the incidence has since declined over the last three years [1].

As an open window into a country, a port is vulnerable to the potential threat of infectious diseases, biological and chemical agents, and radio nuclear materials. Manzhouli, located northeast of the Inner Mongolia neighbors Russia and Mongolia, is the largest land port in China. It is also a key location by which to prevent and control the spread of infectious disease in Russia and Mongolia. Therefore, public health aims include preventing the spread of these infectious diseases and promoting health through the efforts of inspection and quarantine departments.

In order to be successful at these aims, it is necessary to be able to detect and quantify the frequency of infectious diseases. However, there have been few studies concerning this in Manzhouli port. The aims of this study were to assess the frequency of infectious disease upon entry/exit screening, focusing on syphilis, hepatitis B and C, and human immunodeficiency virus (HIV), and explore the potential risk for becoming infected based on occupation at Manzhouli port. Our analysis will help promote understanding of the presence and spread of infectious diseases in ports and guide future infectious disease control strategies in Manzhouli port.

\section{Materials and Methods}

This study examined data collected from Manzhouli port from January 2012 through December 2014 by the Manzhouli International Travel Healthcare Center (ITHC) during the entry/exit screening of people. One category of data collected during this study was the occupation of the people screened, which included businessmen, government officials, contract workers, overseas students, traffic staff, international travelers, foreigners and those married abroad. We selected the two variables for analysis of infection associated with the occupation of people entering/exiting the port and the year.

Several laboratory tests were used to positively diagnose those with infectious diseases of interest. To detect syphilis, which is caused by Treponema pallidum, the Treponema pallidum particle agglutination assay (TPPA, INTEC Bio-Technology Co., Xiamen) and toluidine red unheated serum test (TRUST, Rongsheng Bio-Pharmaceutical Co., Shanghai) were used. To detect infection with hepatitis B and C viruses, the presence of hepatitis B surface antigen (HBsAg) and hepatitis C specific antibodies (HCV-Ab) was measured, respectively, using the rapid colloidal gold method (Aicon Bio-Technology Co., Hangzhou) and enzyme linked immunosorbent assay (ELISA, INTEC Bio-Technology Co., Xiamen). To detect infection with the human immunodeficiency virus (HIV), the causative agent of AIDS, the electroselenium method (designated by The General Administration of Quality Supervision, Inspection and Quarantine of the People's Republic of China, AQSIQ) and ELISA (BioMérieux Kit, France) were used to measure HIV specific antibodies (HIV-Ab). All samples that tested positive for HIV-Ab were sent to the Inner Mongolia ITHC and confirmed by Western Blot (WB).

The frequency of each infectious disease was calculated and tested for an association with occupation and year of occurrence. Microsoft Excel software (Microsoft, Co., Redmond, WA, USA) and SPSS 13.0 statistical software (IBM SPSS, Inc., Chicago, IL, USA) were used for data management and analyses. The $\chi^{2}$ test was used to test for statistical significance, which was set at a $\mathrm{p} \leq 0.05$ (two-sided).

\section{Results}

Between 2012 and 2014, 16,152 entry/exit screens were performed and recorded by the Manzhouli ITHC. Table 1 lists the occupations of the people screened during this period. Nearly half were contract workers, while more than $30 \%$ of were businessmen.

Table 2 lists the infectious diseases and the frequency of a positive diagnosis in people entering and exiting from 2012-14. A total of 271 people were determined to be HBsAg positive with a constituent ratio of more than $70 \%$. Less than $2 \%$ of entry-exit people were HIV-Ab positive.

Table 3 presents the frequency of the infectious diseases of interest for the different occupations of people entering and exiting via the port during this period. The total proportion of infectious diseases identified within the population was $2.18 \%$. Interestingly, there was a significant difference in the number of infectious diseases detected over the three years studied $\left(\chi^{2}=515.19, \mathrm{p}<0.001\right)$. Subjects were positive for HBsAg the most frequently of the diseases tested at $1.68 \%$ of the population, followed by syphilis, HCV-Ab and then HIV-Ab 
Table 1. Occupation of people entering and exiting via Manzhouli port, 2012-2014.

\begin{tabular}{ccc}
\hline Occupation & Physical examinees (case) & Percentage (\%) \\
\hline Businessman & 5122 & 31.72 \\
Government official & 103 & 0.63 \\
Contract worker & 7999 & 49.52 \\
Overseas student & 882 & 5.46 \\
Traffic staff & 763 & 4.72 \\
International traveler & 656 & 4.06 \\
Foreigner & 488 & 3.03 \\
Married abroad & 139 & 0.86 \\
Total & 16,152 & 100.00 \\
\hline
\end{tabular}

Table 2. Frequency of infectious diseases in Manzhouli port, 2012-2014.

\begin{tabular}{ccc}
\hline Infectious diseases & Positive (case) & Percentage (\%) \\
\hline Syphilis & 37 & 10.63 \\
Hepatitis B & 271 & 77.87 \\
Hepatitis C & 34 & 9.77 \\
HIV & 6 & 1.72 \\
Total & 348 & 100.00 \\
\hline
\end{tabular}

Table 3. The frequency of infectious disease among different occupations in Manzhouli port, 2012-2014.

\begin{tabular}{|c|c|c|c|c|c|c|c|c|c|c|}
\hline \multirow{3}{*}{ Occupation } & \multicolumn{2}{|c|}{ Syphilis } & \multicolumn{2}{|c|}{ HBsAg } & \multicolumn{2}{|c|}{ HCV-Ab } & \multicolumn{2}{|c|}{ HIV-Ab } & \multicolumn{2}{|c|}{ Total } \\
\hline & Positive & Rate & Positive & Rate & Positive & Rate & Positive & Rate & Positive & Rate \\
\hline & (case) & (\%) & (case) & (\%) & (case) & (\%) & (case) & (\%) & (case) & (\%) \\
\hline Businessman & 5 & 0.10 & 21 & 0.41 & 2 & 0.04 & 1 & 0.02 & 29 & 0.62 \\
\hline Government official & 1 & 0.97 & 0 & 0 & 0 & 0 & 0 & 0 & 1 & 0.97 \\
\hline Contract worker & 24 & 0.30 & 156 & 1.95 & 13 & 0.16 & 4 & 0.05 & 197 & 2.46 \\
\hline Overseas student & 1 & 0.11 & 6 & 0.68 & 0 & 0 & 0 & 0 & 7 & 0.79 \\
\hline Traffic staff & 1 & 0.13 & 12 & 1.57 & 8 & 1.05 & 0 & 0 & 21 & 2.75 \\
\hline International traveler & 0 & 0 & 2 & 0.30 & 0 & 0 & 0 & 0 & 2 & 0.30 \\
\hline Foreigner & 3 & 0.61 & 69 & 14.14 & 10 & 2.05 & 1 & 0.20 & 83 & 17.21 \\
\hline Married abroad & 2 & 1.44 & 5 & 3.60 & 1 & 0.72 & 0 & 0 & 8 & 5.76 \\
\hline Total & 37 & 0.23 & 271 & 1.68 & 34 & 0.21 & 6 & 0.04 & 348 & 2.18 \\
\hline
\end{tabular}

positive, which occurred in $0.23 \%, 0.21 \%$ and $0.04 \%$ of people tested, respectively. Among HBsAg positive people, foreigners tested positive at a significantly higher than any other occupation. A similar trend was observed for the HCV-Ab and HIV-Ab positive population. Among those who tested positive for syphilis, the most frequently affected population was those married abroad.

Table 4 shows the rate of detection for the infectious diseases of interest over the three year study period. There was a significant difference in the number of infected people between these three years $\left(\chi^{2}=105.77\right.$, p $<$ 0.001). The highest number of cases occurred in 2014 at 3.35\% of the people screened, while the lowest was in 2013 at $0.81 \%$. The number of HBsAg positive people $\left(\chi^{2}=137.17, \mathrm{p}<0.001\right)$ was highest in 2014. Meanwhile, syphilis $\left(\chi^{2}=4.71, \mathrm{p}=0.095\right)$ occurred at the same frequency in 2012 and 2014. The number of HCV-Ab 
Table 4. The frequency of infectious disease among people in Manzhouli port from 2012 to 2014.

\begin{tabular}{cccccccccccc}
\hline & \multicolumn{2}{c}{ Syphilis } & \multicolumn{2}{c}{ HBsAg } & \multicolumn{2}{c}{ HCV-Ab } & \multicolumn{2}{c}{ HIV-Ab } & \multicolumn{2}{c}{ Total } \\
\cline { 2 - 12 } Years & Positive & Rate & Positive & Rate & Positive & Rate & Positive & Rate & Positive & Rate \\
\cline { 2 - 12 } & (case) & $(\%)$ & (case) & $(\%)$ & (case) & $(\%)$ & (case) & (\%) & (case) & $(\%)$ \\
\hline 2012 & 8 & 0.30 & 46 & 1.75 & 13 & 0.49 & 3 & 0.12 & 70 & 2.70 \\
2013 & 9 & 0.13 & 33 & 0.49 & 10 & 0.15 & 1 & 0.01 & 53 & 0.81 \\
2014 & 20 & 0.30 & 192 & 2.85 & 11 & 0.16 & 2 & 0.03 & 225 & 3.35 \\
\hline
\end{tabular}

positive $\left(\chi^{2}=12.06, \mathrm{p}=0.002\right)$ was higher in 2012. Also, the frequency of HIV-Ab positive subjects trended higher in 2012, but had no significant differences compared to 2013 and 2014 after examination $\left(\chi^{2}=4.13\right.$, p $=$ 0.127).

\section{Discussion}

In this study, we measured the occurrence of certain infections in Manzhouli port to establish the magnitude of infectious disease and to provide data for public health and quarantine planning. Hepatitis B was the most common infectious disease found either inland or port. In China, around 130 million people are carriers of HBsAg with 30 million people chronically infected and 300,000 deaths from hepatitis B-related diseases annually [2]. Our results suggest that the frequency that HBsAg positive people were detected in Manzhouli port was lower than some ports, such as Qingdao (2.41\%), Lianyungang (2.03\%) and Dalian (2.29\%) [3]-[5]. However, the number of people entering and exiting via Manzhouli was less than the aforementioned ports. Hepatitis B vaccinations may also play a role in the lower rates of infection at Manzhouli port, as emphasized by the ITHC. In addition, foreigners and those married abroad were most likely to be HBsAg positive. This phenomenon can be attributed to the higher prevalence of hepatitis B in Mongolia and Russia Far East [6]. Similarly, contract workers and traffic staff were also more likely to be HBsAg positive, which may be related to the overall lower education level within these cohorts. Cross infection of hepatitis B is associated with a crowded living environment, poor living conditions and low quality health services [7]. Therefore, these populations are of particular interest, and therefore, were paid close attention.

In comparison with hepatitis B, the frequency of hepatitis C was lower. About 500,000 HCV-related deaths are seen globally each year [8]. In China, about 6 million people were estimated to be infected with HCV [9] with the highest burden in absolute numbers on the world [10]. Our work suggests that the occupations that most frequently test HCV-Ab positive were similar to those who were HBsAg positive in Manzhouli port. This phenomenon reflected the higher prevalence of hepatitis $\mathrm{C}$ in neighboring countries. To our knowledge, Mongolia has the highest prevalence of hepatitis $\mathrm{C}$ in the world [11]. Contract workers and traffic staff had a higher rate because the route of transmission of HCV parallels HBV. However, no effective vaccine is available to help prevent HCV. Thus, it is necessary to strengthen the surveillance of HCV, and educate incoming and egressing people on $\mathrm{HCV}$.

In this study, syphilis was detected in $0.23 \%$ of the population tested. It was higher than some ports, such as Dalian (0.17\%) [5] and Luobei (0.16\%) [12], however, it was lower than others, such as Lianyungang (0.47\%) [4]. As early as 50 years ago, cases of syphilis were nearly nonexistent. However, with changes in the process of reform and opening, syphilis is no longer controlled and cases have resurged over the last decade [13]. Our results suggest that people married abroad, foreigners and contract workers had the highest rates of syphilis. One reason this may be is that the frequency of syphilis is high in Mongolia and Russia because being a sex worker is a legally acceptable occupation [14]. For another, syphilis was more common in contract workers due to an overall lower education levels, multiple sexual partners and the history of sexual intercourse [15]. Although the number of syphilis cases among government officials was high in our study, this result may be skewed by the small sample size of subjects with this occupation. As there is no effective vaccine available against syphilis, surveillance of focus points and the target population, as well as education about syphilis control need to be strengthened.

HIV continues to be a major global public health issue, as 1.2 million people died from HIV-related causes globally in 2014 [16]. In our study, $0.04 \%$ of subjects were HIV-Ab positive. This is consistent with the number 
of cases in other ports [17]. Foreigners, contract workers and businessmen were diagnosed HIV-Ab positive, which may be related to their occupation. As with syphilis, the increased frequency of HIV among foreigners may be attributed to the legality of sex workers in their home country [18]. HIV, HBV and HCV have common routes of transmission that involve certain risky behaviors [11]. For example, contract workers are associated with risky sexual behavior, while businessmen are associated with the injection of drugs. Therefore, these populations should be recognized as a key population at risk for HIV and in need of HIV prevention efforts.

An overall regular trend was not found for these four infectious diseases over the course of this study. There are two possible reasons for this. First, three years may have been too short of a study period to detect any trends. Second, in Manzhouli port, the report of detection rate was emphasized in 2014 and, thus, the detection of infectious diseases was highest in 2014. Therefore, a longer period of observation is necessary to explore the frequency of infectious diseases over time.

\section{Conclusion}

Together, our findings confirm hepatitis B as an important infectious disease in Manzhouli port, which indicates that an increase in intervention is necessary, especially for foreigners, contract workers and traffic staff. Other infectious diseases should also continue to be under surveillance. Identifying the populations at risk could offer important information that would help plan and execute effective public health interventions to prevent and control disease among those entering and exiting via Manzhouli port.

\section{References}

[1] Wand, L.P., Zeng, L.J., Ren, X., Geng, M.J., Li, Z.J. and Yu, H.J. (2015) Analysis of Morbidity and Mortality Characteristics of the Notifiable Diseases Reported in 2013 in China. Chinese Journal of Epidemiology, 36, 194-198.

[2] Jia, J.-D. and Zhuang, H. (2004) Seminar Meeting Minutes of China Chronic Hepatitis B Treatment Advances. Chinese Journal of Hepatology, 63-64.

[3] Zhang, J., Xue, X.-N., Xu, H.-F., Chen, X.-G., Zhang, J., Zhang, Q., Zhu, K. and Lin, Y. (2015) Prevalence of HBsAg among International Travelers at Qingdao Port from 2009 to 2013. Chinese Frontier Health Quarantine, 21-24-29.

[4] Wang, J. (2015) Analysis on Infectious Diseases Monitoring Results among Entry-Exit Personnel at Lianyungang Port from 2005 to 2014. Chinese Frontier Health Quarantine, 254-257.

[5] Zhao, L., Jia, H., Shi, J., Shi, F.-L. and Li, Y.-F. (2015) Analysis on Surveillance Results of Infectious Diseases and Epidemiological Characteristics among Entry-Exit Personnel at Dalian Port from 2010 to 2013. Chinese Frontier Health Quarantine, 25-29.

[6] WHO in Hepatitis B (2015) World Health Organization Media Centre. http://www.who.int/mediacentre/factsheets/fs204/en/

[7] Li, S.M. and Luo, N. (2007) Infectious Diseases Surveillance among Entry-Exit Personnels at Panyu Port. Chinese Frontier Health Quarantine, 30, 20-23.

[8] WHO in Hepatitis C (2015) World Health Organization Media Centre. http://www.who.int/mediacentre/factsheets/fs164/en/

[9] Chen, Y.S., Li, L., Cui, F.Q., Xing, W.G., Wang, L., Jia, Z.Y., Zhou, M.G., Gong, X.H., Wang, F.Z. and Zheng, H. (2011) A Sero-Epidemiological Study on Hepatitis C in China. Chinese Journal of Epidemiology, 32, 888-891.

[10] William, S., Ibrahim, A., Razavi, H.A., Ayman, A., Ali, A.E., Ahmed, A.O., Deepak, A., Chen, C.H., Dou, X. and Hisham, E.K. (2011) A Systematic Review of Hepatitis C Virus Epidemiology in Asia, Australia and Egypt. Liver International, 31, 61-80. http://dx.doi.org/10.1111/j.1478-3231.2011.02540.x

[11] Asghar, A. (2012) Analysis of Hepatitis C Burden, Determinants and Prevention \& Control Strategies Globally and in Pakistan. KIT-Royal Tropical Institute.

[12] Liang, H.J., Wang, F.S., Wang, H.Y. and Zhao, G.T. (2014) Analysis of Infectious Disease Finding among Exit Personnel at Luobei Port from 2000 to 2010. Prev Med Trib, 1, 56-57.

[13] Chen, Z.Q., Zhang, G.C., Gong, X.D., Lin, C., Gao, X., Liang, G.J., Yue, X.L., Chen, X.S. and Cohen, M.S. (2007) Syphilis in China: Results of a National Surveillance Programme. Lancet, 369, 132-138. http://dx.doi.org/10.1016/S0140-6736(07)60074-9

[14] Karapetyan, A.F., Sokolovsky, Y.V., Araviyskaya, E.R., Zvartau, E.E., Ostrovsky, D.V. and Hagan, H. (2002) Syphilis among Intravenous Drug-Using Population: Epidemiological Situation in St Petersburg, Russia. International Journal of STD \& AIDS, 13, 618-623. http://dx.doi.org/10.1258/09564620260216326 
[15] Qu, J.W., Ma, B.Y., Liu, W., Xiang, H., Xiong, T.T. and Nie, S.F. (2015) Epidemiological Analysis of Syphilis at Frontier Ports of China. Chinese Journal of AIDS \& STD, 2, 145-147.

[16] WHO in HIV/AIDS (2015) World Health Organization Media Centre. http://www.who.int/mediacentre/factsheets/fs360/en/

[17] Liu, S.Y., Zhu, Y.-L., Liu, C.F., Liu, W., Gu, L.B., Zhen, S.X., Li, D.X., Zhang, D.F., Dong, R.L. and Liu, J. (2013) Analysis on Surveillant Result of HIV Infection among Entry-Exit Personnel at Shenzhen Port. Chinese Frontier Health Quarantine, 4, 217-219.

[18] Enkhbold, S., Tugsdelger, S., Morita, S., Sakamoto, J. and Hamajima, N. (2007) HIV/AIDS Related Knowledge and Risk Behaviors among Female Sex Workers in Two Major Cities of Mongolia. Nagoya Journal of Medical Science, 69, 157-165. 